\title{
ESCOLARIZAÇÃO, CULTURAS E INSTITUIÇÕES: ESCOLAS ÉTNICAS ITALIANAS EM TERRAS BRASILEIRAS
}

\author{
ESCUELA, CULTURAS E INSTITUCIONES: ESCUELAS \\ ÉTNICAS ITALIANAS EN TIERRAS BRASILEÑAS \\ SCHOOLING, CULTURES AND INSTITUTIONS: ITALIAN \\ ETHNIC SCHOOLS IN BRAZILIAN LANDS \\ ESCOLARISATION, CULTURES ET INSTITUTIONS: ÉCOLES \\ ETHNIQUES ITALIENNES SUR LE TERRITOIRE BRÉSILIEN
}

Gisele Belusso $^{1}$

LUCHESE, Terciane Ângela (Org.). Escolarização, culturas e instituições: escolas étnicas em terras brasileiras. Caxias do Sul, RS: Educs, 2018.

A organizadora da obra é professora da graduação e da pós-graduação,

${ }^{1}$ Universidade de Caxias do Sul (UCS), Caxias do Sul/RS, Brasil. 
nos Programas de Pós-graduação em História e em Educação da Universidade de Caxias do Sul. Além disso, ela é líder do grupo de pesquisa História, Educação, Imigração e Memória (Grupheim²), no qual os integrantes têm especial interesse no campo da História da Educação e a marca da presença de diferentes grupos étnicos, seus processos de escolarização e as culturas escolares. A presente obra apresenta resultados de pesquisa tanto de integrantes do Grupheim quanto de pesquisadores convidados, estabelecendo assim uma profícua interlocução com múltiplas perspectivas acerca do tema proposto para trabalho: as escolas étnicas instituídas no Brasil, com ênfase na escolarização, culturas e instituições escolares. Os capítulos apresentados têm como marco inicial o momento de intensificação das massas imigratórias italianas no Brasil, fim do século XIX e marco final a década de 1940 quando do fechamento das últimas escolas étnicas em decorrência do acirramento da nacionalização de ensino.

A obra é composta por nove capítulos, antecedidos pelo prefácio escrito pelo reconhecido pesquisador Angelo Trento, publicado na íntegra em duas línguas: português e italiano. A apresentação ficou sob a responsabilidade da organizadora da obra Terciane Ângela Luchese. Ao final do livro encontram-se ainda as informações sobre os autores, situando o leitor sobre os contextos em que se inserem cada pesquisador.

Já no prefácio, Angelo Trento destaca a contribuição da obra aos interessados pelo tema de pesquisa. Afirma que são inúmeros os estudos sobre imigração italiana no Brasil, no entanto, a escolarização foi um dos temas que pouca atenção mereceu inicialmente por parte dos pesquisadores. Contribuição que inclusive pode oportunizar aprofundamentos futuros. Em sua escrita situa o leitor em relação ao que representava a escola étnica no projeto de manter o “[...] senso de pertencimento comum e de ligação à Pátria [...]”, referindo-se a

\footnotetext{
2 Também é membro do Grupo de Pesquisa Educação no Brasil: memória, instituições e cultura escolar (Ebramic). É bolsista Produtividade em Pesquisa desde 2013 e integra a rede transnacional Transfopress (França-Brasil). Tem consolidada produção na área da História da Educação e na temática proposta para obra resenhada que se adensaram, em especial, a partir de sua tese de doutorado (LUCHESE, 2008).
} 
pátria italiana, e as formas com que o governo italiano contribuiu para manter tais instituições de duração efêmera no Brasil. Pontua, por fim, as potencialidades, as lacunas e as relações possíveis a partir dos capítulos apresentados, sinalizando inclusive possiblidades para os citados aprofundamentos, elogiando a iniciativa editorial.

Logo após, na apresentação, Luchese (2018) esclarece que houve uma lógica de organização dos capítulos, privilegiando nos quatro primeiros a cultura material escolar, seguidos de três capítulos com ênfase nas culturas e processos escolares e encerrando com dois capítulos dedicados às escolas italianas de nível secundário. Tal cuidado editorial oportuniza uma leitura muito aprazível ao longo das 281 páginas.

Adentrando aos capítulos, o primeiro deles foi intitulado de Livros didáticos e italianidade no Brasil nos anos 1920-1930, o qual é de autoria do pesquisador italiano Alberto Barausse, atualmente residente no Brasil, em que se propõe a transitar entre a cultura material escolar e a constituição de uma identidade nacional italiana. $\mathrm{O}$ autor coloca em perspectiva a produção de livros para as escolas no exterior, que impulsionou o interesse do governo italiano e os desdobramentos a partir de então. Diante do contexto exposto, ele identifica dois livros que circularam no Rio Grande do Sul: as obras Cuore Lontano e Italia Lontana, os quais tinham como cenário da narrativa um ano escolar, enfatizando a presença de italianos em outros países os representando como sujeitos de passagem nesses locais distantes de sua Pátria. A partir de então incitando a constituição de uma formação étnico-identitária, pautada também no respeito ao Brasil representada nas obras como a terra hospedeira. Barausse sinaliza também os conteúdos dos livros, os quais foram selecionados e utilizados para dar coerência ao "sentimento nacional e ao culto da pátria", caracterizando as obras como nacionalistas moderadas, pois "[...] exprimiam o valor do conservadorismo social; refletiam um contexto fortemente classista e assinalavam uma discriminação racial” (BARAUSSE, 2018, p. 44).

A seguir, Barausse (2018, p. 47) relaciona a produção de livros 
publicados na Itália com a pedagogia fascista de Mussolini em que as escolas eram consideradas como "ferramentas para apoiar a política externa [...]". No entanto, o autor modaliza o discurso ao levar em consideração que os usos feitos pelos livros no território brasileiro podem ser vários e não garantem sua exclusividade. Além disso, Barausse, debruça-se sobre a estrutura e as características de tais livros, bem como de seus autores e editores, para os diferentes graus de escolarização que "[...] parecem recolher algumas sugestões da pedagogia ativa" (BARAUSSE, 2018, p. 52). Desta forma, ao longo do texto, o pesquisador evidencia que a produção de livros na Itália para as escolas étnicas em território brasileiro não pode ser considerada uniforme. Tendo em vista, que a mesma sofreu diferentes influências políticas e ideológicas, assim adequando o tom das narrativas que compuseram os livros que chegaram ao Brasil. $\mathrm{O}$ capítulo inicial da obra é denso e o mais extenso da obra, trazendo muitos elementos específicos ao que se propõe e oportunizando uma interessante articulação com os textos a seguir.

O segundo capítulo, A cultura material das escolas coloniais italianas no Paraná: da precariedade à renovação, de Elaine Cátia Falcade Maschio, analisa a realidade das instituições públicas de ensino em regiões rurais do Paraná para compreender os espaços físicos, mobiliários e materiais escolares destinados a elas. A pesquisadora argumenta que inicialmente os espaços físicos foram improvisados e não necessariamente eram exclusivos para instituição escolar. Espaços que por vezes eram alugados ou simplesmente disponibilizados pelas comunidades. No entanto, isso foi alterando-se a partir do momento que $o$ governo paranaense investiu na construção de prédios escolares com especificidades definidas em relação ao número de salas e do mobiliário escolar.

Cria-se assim a possibilidade da reunião de várias aulas em um só prédio, instituindo, desta forma, os grupos escolares ou as escolas reunidas, em espaços que passam a ser mantidos pelo poder público. Da mesma forma, o mobiliário escolar passou de móveis emprestados ou comprados à custa dos professores, para móveis projetados e custeados pelo poder público em especial 
a partir de 1920. Momento em que também houve a preocupação em prover as instituições com os materiais escolares. $\mathrm{O}$ que ocorreu de forma privilegiada para as escolas das áreas centrais e grupos escolares e, somente mais tarde, para as escolas coloniais.

Adiante, o terceiro capítulo intitulado Leituras aos alunos das escolas elementares paulistas, públicas e subsidiadas, de Eliane Mimesse Prado, analisa a indicação de leituras propagadas nos periódicos produzidos para leitores imigrantes de descendência italiana que circulavam no Brasil que "[...] contribuíram com a possibilidade de reflexão sobre outros livros, além dos indicados nos programas de ensino" (PRADO, 2018, p. 103). Na esteira da discussão, fica notória a precariedade dos livros didáticos enviados pelo governo italiano ao Brasil, que nem sempre eram os mais atualizados e não eram fornecidos em número suficiente no início do século XX. A pesquisadora argumenta que embebidos da concepção de que a leitura tinha uma função moral a Associação Dante Alighieri e os periódicos indicavam outros livros que eram considerados leituras imprescindíveis aos filhos dos imigrantes. A autora mapeou várias indicações e as caracterizou, justificando a sua pretensa leitura e os motivos vinculados a manutenção de um sentimento de "amor à pátria" (PRADO, 2018, p. 116).

O quarto capítulo, "Nós queimamos um caixão de livros": memórias dos tempos de escola de imigrantes italianos no Sul do Brasil, de Clarícia Otto, apresenta uma análise a partir das memórias dos descentes italianos em Santa Catarina, identificando significados atribuídos às experiências escolares. A pesquisadora argumenta que fazem parte das memórias e tem como pontos de contato no quadro social: os locais de funcionamento, os tempos escolares, os materiais didáticos, as práticas, os saberes, a marca da religiosidade e a preocupação com uma identidade italiana. As memórias ainda se vinculam a quadros sociais familiares e étnicos. Memórias que também foram entremeadas pelo contexto da nacionalização do ensino e que foram marcadas pelas lembranças da proibição da fala do dialeto italiano e da preocupação das 
famílias em eliminar a presença de livros e de jornais em língua italiana não só das escolas, mas também de suas residências. Assim, o quarto capítulo além de fazer articulação com os capítulos anteriores, também, faz o fechamento da parte inicial da obra destinada à cultura material escolar.

Para iniciar os capítulos acerca das culturas e processos escolares Claudia Panizzolo apresenta $O$ processo escolar entre italianos e seus descendentes: a escola italiana em São Paulo, no século XIX e início do século $X X$. O capítulo marca de maneira significativa o contexto imigratório em São Paulo, que tem algumas singularidades como bairros povoados por imigrantes de diferentes regiões da Itália, com dialetos próprios e bairristas em preservar regionalismos étnicos. Foi nesse contexto que se inseriram as escolas étnicas que funcionavam em São Paulo, vinculadas as sociedades de Mútuo Socorro. A pesquisadora tensiona em suas escritas os discursos produzidos sobre as escolas italianas a partir de professores vinculados a Sociedade Dante Alighieri, de professores brasileiros vinculados à Diretoria da Instrução Pública e da imprensa italiana e brasileira que propagaram representações, por vezes discordantes, sobre as instituições. Desta forma, caracteriza as escolas como espaços de disputa para italianizar ou paulistanizar os alunos ali matriculados.

Em seguida, Terciane Ângela Luchese, no sexto capítulo intitulado Por dentro da escola italiana: um olhar para a escola da Sociedade Regina Margherita na Colônia Dona Isabel/RS (1882-1889), enfoca inicialmente a discursividade que emergiu a partir das políticas do governo italiano para ofertar escolarização aos emigrados e coloca em perspectiva as Sociedades de Mútuo Socorro nesse contexto. Conforme Luchese (2018, p. 186), as mencionadas sociedades foram característica marcante deste grupo étnico, que "[...] foram centros de difusão e construção de laços de pertencimento (italianitá) e difundiram a escolarização, mesmo que não em sua unanimidade”. O capítulo decore justamente a partir de uma dessas entidades que surge na região nordeste do Rio Grande do Sul, em 1882, e que abre uma escola em 1883: a Sociedade de Mútuo Socorro Regina Margherita. 
Desta forma, a autora adentra a escola italiana analisando desde os documentos que tratam da abertura da instituição, seu espaço físico, funcionamento, até a compra e recebimento de materiais escolares, mobiliário, professores, as condições de admissão de alunos, a organização dos tempos na escola e também como mantinha-se financeiramente. Além de indícios sobre a atuação do conselho escolar vinculado à sociedade.

A seguir, escrito à quatro mãos, Renata Brião de Castro e Patrícia Weiduschadt, no sétimo capítulo intitulado Escolas étnicas italianas no município de Pelotas (RS) (1883-1937): constituição e percursos, colocam em perspectiva as escolas étnicas da região sul do Rio Grande do Sul. Primeiramente as autoras contextualizam a imigração italiana nessa região e suas particularidades, em especial na convivência com outras etnias na chegada em uma cidade já consolidada. Após, argumentam que as escolas étnicas em Pelotas não se restringiram ao meio urbano e, apesar de terem breves indícios, afirmam terem existido nas áreas rurais. No tocante as associações de Mútuo Socorro as autoras as compreendem como espaços não formais de educação. A profusão de escolas étnicas em Pelotas justificou-se pelo grande contingente de imigrantes italianos na cidade, fazendo com que funcionassem concomitantes as escolas públicas já instituídas em Pelotas.

Por fim, os últimos dois capítulos evidenciam escolas italianas de nível secundário. $\mathrm{O}$ oitavo capítulo intitulado De repente, a Itália é inimiga: o Instituto Médio Ítalo-Brasileiro Dante Aligheri (São Paulo, 1911-1945), de autoria de Fernanda Franchini e Diana Vidal, explicita o processo de nacionalização nessa instituição, após a declaração de guerra do governo brasileiro ao Eixo em 1942. As autoras afirmam que antes mesmo desse momento a instituição já sofria pressões tanto do governo brasileiro como do governo italiano com relação aos programas de ensino e as identidades propostas. No entanto, não deixou de ser uma marca característica da instituição a presença dos professores italianos, o ensino da língua e os ritos e as cerimônias oriundos da cultura italiana que ocorrem até o ano de 1942. 
A partir de então a instituição teve a direção assumida por um brasileiro e sofreu um processo sob a acusação da desnacionalização do ensino e da implementação da política fascista, sendo incluídos no inquérito doze professores. O nome da instituição passou a ser Colégio Visconde de São Leopoldo e várias ações foram concretizadas, como por exemplo, a recolha de livros entendidos como fascistas, a implementação de comemorações de datas nacionais e a remoção de símbolos que remetessem a cultura italiana. Diante de tal intervenção, voltou a ser denominada Dante Alighieri na década de 1950, momento em que também retomou os cursos de língua e literatura italiana.

O autor Gelson Leonardo Rech no último capítulo da obra apresenta $O$ Instituto Ítalo-brasileiro Augusto Menegatti de Porto Alegre. O único colégio interno na época que ofertava o Ensino Elementar e o Curso técnico que surgiu na capital do Rio Grande do Sul, um local com um grande contingente de imigrantes italianos que divulgavam suas aspirações e suas necessidades por meio dos jornais e sua cultura nas sociedades de mútuo socorro, com o intuito de manter a italianidade. São também os periódicos, utilizados pelo pesquisador como documento, que apresentam indícios sobre a abertura do instituto oficialmente no ano de 1917, nitidamente destinado à elite italiana e a manutenção de novos membros dessa elite. Rech (2018) perscrutando os periódicos apresenta a proposta de ensino do instituto, a representação acerca do diretor da instituição, as mudanças de denominações da mesma, além da duração do Curso elementar e Técnico e as suas respectivas disciplinas, o regulamento dentre outras informações. Elementos divulgados nos periódicos associados à representação de que o "[...] colégio seria uma grande família, em que o afeto e a ternura reinariam [...]" discurso de acolhida divulgado em prol de angariar alunos de diferentes locais do Estado para frequentar em regime de internato a instituição (RECH, 2018, p. 251). O pesquisador destaca que para atender o selecionado público os professores eram "destaque na sociedade porto-alegrense".

O instituto foi, por um período, subsidiado pelo governo italiano com 
recursos financeiros, o que lhe incumbia de seguir os programas determinados por eles e prestar-lhes contas, além de ser fiscalizado por cônsules italianos. Apesar de atender predominantemente o público masculino o autor apresenta indícios de que existiu também a presença feminina no instituto. Em torno de 1930 encerraram-se as suas atividades, no entanto, ele teve uma longa trajetória assim considerada pelo pesquisador em contraponto a existência efêmera das escolas da Região Colonial Italiana, conforme citado por Luchese nesta obra.

Por fim, considero um livro complexo de ser resenhado pela qualidade e pela quantidade de reflexões propostas, uma preciosidade para aqueles que se interessam pela temática dos processos de escolarização étnicos italianos. A obra foi escrita em colaboração com pesquisadores que colocam em perspectiva diversas regiões do país e suas singularidades articuladas as políticas nacionais e internacionais com o cuidado de não homogeneizar as experiências. Os capítulos em diversos momentos fazem relações entre uma região e outra e vão entrecruzando as narrativas e a complexidade do tema, além de apresentar uma significativa quantidade de documentos. A produção mostra a potencialidade da pesquisa em diferentes grupos de pesquisa e a necessária interlocução entre eles para o avanço na produção de conhecimento na área. Sem dúvida a leitura desta obra torna-se indispensável aos pesquisadores da área e marca a potencialidade da temática da escolarização entre diferentes grupos étnicos, para pensar a história da educação para além das fronteiras nacionais para aprofundar entendimentos, tornando mais complexas e plurais as narrativas históricas da educação. Brechas de novas pesquisas são abertas com a leitura dos resultados apresentados na obra. 


\section{REFERÊNCIAS}

BARAUSSE, Alberto. Livros didáticos e italianidade no Brasil nos anos 19201930. In: LUCHESE, Terciane Ângela (Org.). Escolarização, culturas e instituições: escolas étnicas em terras brasileiras. Caxias do Sul, RS: Educs, 2018. p. 29-74.

LUCHESE, Terciane Ângela (Org.). Escolarização, culturas e instituições: escolas étnicas em terras brasileiras. Caxias do Sul, RS: Educs, 2018.

LUCHESE, Terciane Ângela. O processo entre imigrantes da região colonial italiana do RS - 1875 a 1930: leggere, scrivere e calcolare per essere alcuno nella vita. 2008. 495 f. Tese (Doutorado) - Programa de PósGraduação em Educação, Universidade do Vale do Rio dos Sinos, São Leopoldo, 2008.

LUCHESE, Terciane Ângela. Por dentro da escola italiana: um olhar para a escola da Sociedade Regina Margherita na Colônia Dona Isabel/RS (18821889). In: LUCHESE, Terciane Ângela (Org.). Escolarização, culturas e instituições: escolas étnicas em terras brasileiras. Caxias do Sul, RS: Educs, 2018. p. 173-206.

PRADO, Eliane Mimesse. Leituras sugeridas aos alunos das escolas elementares paulistas, públicas e subsidiadas. In: LUCHESE, Terciane Ângela (Org.).

Escolarização, culturas e instituições: escolas étnicas em terras brasileiras. Caxias do Sul, RS: Educs, 2018. p. 99-118.

RECH, Gelson Leonardo. O instituto ítalo-brasileiro Augusto Menegatti de Porto Alegre. In: LUCHESE, Terciane Ângela (Org.). Escolarização, culturas e instituições: escolas étnicas em terras brasileiras. Caxias do Sul, RS: Educs, 2018. p.245-280.

GISELE BELUSSO é pedagoga, Mestra em Educação e doutoranda em Educação pela Universidade de Caxias do Sul. Bolsista Capes. Pesquisadora membro do Grupo de Pesquisa em História da Educação, Imigração e Memória (Grupheim).

E-mail: giselebelusso@hotmail.com

(D) http://orcid.org/0000-0003-1721-477X 
Revista História da Educação (Online), 2019, v. 23: e89475 DOI: http://dx.doi.org/10.1590/2236-3459/89475
e-ISSN: 2236-3459

http://seer.ufrgs.br/asphe

Recebido em: 09 de janeiro de 2019

Aprovado em: 10 de maio de 2019

(c) (1)

Associação Sul-Rio-Grandense de Pesquisadores em História da Educação - Asphe

Artigo de acesso aberto distribuído nos termos de licença Creative Commons. 